\title{
Problema gerador de discussões: uma metodologia para o ensino em Engenharia
}

\author{
Discussions generator problem: a methodology for
}

teaching in Engineering

Vinícius Machado

Nilcéia Aparecida Maciel Pinheiro

\begin{abstract}
Resumo
Apresenta-se, nesse trabalho, a proposta de uma metodologia específica para o ensino de Ciência e Matemática nos cursos de Engenharia por meio de Problemas Geradores de Discussões. Os PGDs são elaborados a partir de situações contextualizadas e voltadas para o curso de Engenharia exigindo a participação efetiva dos alunos em todo o processo de sua resolução: confronto de idéias, aplicação de conhecimentos científicos, busca de novos conhecimentos, desenvolvimento de raciocínio, realização de atividades experimentais, relacionamento de conhecimentos científicos e tecnológicos com questões sociais e ambientais, entre outros. Apresenta-se também o relato de uma atividade PGD que foi aplicada junto a acadêmicos de Engenharia de Produção da Universidade Tecnológica Federal do Paraná, câmpus Ponta Grossa, na disciplina de Física Geral I.
\end{abstract}

Palavras-chave: ensino, Física, problema gerador de discussões.

\begin{abstract}
This work presents the proposal for a specific methodology for teaching Science and Mathematics in Engineering's courses through Problems Generators of Discussions. The PGDs are prepared from situations contextualized in engineering requiring the effective participation of students in the whole process of resolution: confrontation of ideas, application of scientific knowledge, search for new knowledge, development of reasoning, implementation of experimental activities, relationship of science and technology with social and environmental issues, among others. It is presented in this work too the report of an activity that PGD has been applied with the students of Engineering Production of the Federal Technological University of Parana, Campus Ponta Grossa, in the discipline of Physics I.
\end{abstract}

Keywords: teaching, Physics, discussions generator problems. 


\section{Introdução}

Em pleno século XXI, a sociedade brasileira passa por transformações decorrentes do crescente desenvolvimento Científico e Tecnológico. Essas transformações iniciaram-se no Brasil, de acordo com Piratelli (2005), na segunda metade do século XX com a instalação em território nacional de indústrias estrangeiras e a importação de tecnologias. Novas indústrias e tecnologias resultaram em novos artefatos ou produtos tecnológicos que, de forma despreocupada, passaram a ser incorporados pela sociedade, ditando novas regras à vida do homem moderno. Como esses produtos eram produzidos? De onde era extraída a matéria prima e a energia necessária para a sua produção? Como os resíduos dessa eram tratados? Tais questionamentos não eram relevantes para o consumidor, tampouco para as indústrias que os produziam, pois ainda não existiam leis ambientais que tratavam da regulamentação do processo de produção industrial. Contudo, o avanço tecnológico na área de comunicação permitiu às pessoas o acesso cada vez mais fácil e rápido de informações e essas passaram a alertar a sociedade sobre os efeitos sociais e ambientais causados pelo mau uso da ciência e/ou produção de certos produtos tecnológicos. Como conseqüência, conforme relatam Auller e Bazzo (2001, p.01):

[...] "foi crescendo o sentimento de que o desenvolvimento científico, tecnológico e econômico não estava conduzindo, linear e automaticamente, ao desenvolvimento do bem-estar social. Após uma euforia inicial com os resultados do avanço científico e tecnológico, nas décadas de 1960 e 1970, a degradação ambiental, bem como a vinculação do desenvolvimento científico e tecnológico à guerra (as bombas atômicas, a guerra do Vietnã com seu napalm desfolhante) fizeram com que a ciência e a tecnologia (C\&T) se tornassem alvo de um olhar mais crítico".

Esse olhar mais crítico sobre a Ciência e Tecnologia despertou preocupações cada vez maiores com os impactos tecnológicos, entre eles, os causados pelo setor de produção. Dessa forma, órgãos governamentais passaram a exigir mudanças nos setores de produção - por meio do estabelecimento de leis ambientais e normas reguladoras - e de ensino profissionalizante estabelecendo novas Diretrizes Curriculares Nacionais. A solicitação de mudanças conjuntas nesses dois setores foi de fato um ato importante, pois, entende-se que não há como dissociar mudanças no setor de produção às mudanças no mercado de trabalho e no processo de formação do profissional que nesse mercado irá atuar.

Ao analisar, de forma especial, as Diretrizes Curriculares Nacionais dos cursos de Engenharia, - DCNs - percebe-se entre seus objetivos a construção do perfil do aluno, futuro egresso em Engenharia, com habilidades e competências que lhe permitam gerenciar as pessoas e 
os processos relacionados à produção. Para tanto, passa-se a exigir da formação acadêmica a construção de um egresso em Engenharia com uma forte formação científica e tecnológica aliada a uma formação para a cidadania (LAUDARES; RIBEIRO, 2000). Uma formação que capacite esse profissional a modificar sua postura, seus procedimentos e flexibilizar seus equipamentos, adaptando-se às necessidades dos clientes (BELHOT, 2005). Uma formação que permita ao profissional contribuir de forma efetiva para que a empresa possa atuar de forma competitiva, antecipando as necessidades do mercado de consumo (PÓVOA; BENTO, 2005). Que prepare o egresso para desempenhar várias funções, conforme as exigências se apresentem durante toda a sua vida profissional (SILVEIRA, 2005). É necessária uma formação acadêmica que capacite o aluno científica e tecnologicamente, mas, que também the desenvolva habilidades de planejamento (MEIRELLES, 2005). Uma formação científica, tecnológica e cidadã, permitindo ao egresso em Engenharia atuar profissionalmente e de forma consciente em relação às suas responsabilidades sociais (GORDILLO; GALBARTE, 2002). Nesse sentido, conforme comenta Santos (2005, p.142), o que se espera das universidades é uma formação que prepare esse futuro profissional para que ele possa atuar no setor produtivo compreendendo a necessidade de:

$$
\begin{aligned}
& \text { [...] "ampliar direitos, outrora apenas centrados no homem, de forma a } \\
& \text { garantirem também a integridade do "patrimônio comum da humanidade" e o } \\
& \text { reconhecimento jurídico dum princípio de responsabilidade para com as } \\
& \text { gerações futuras". }
\end{aligned}
$$

Por isso, entende-se que o processo de adaptação do setor de produção e o seu sucesso em atender as exigências governamentais e as demandas do mercado consumidor estão diretamente ligados à capacidade dos seus profissionais em focalizar na sua atuação a busca ao atendimento às exigências que se lhe apresentam. Logo, se mudam os parâmetros de qualidade no processo de produção industrial também devem mudar os parâmetros da formação acadêmica dos profissionais que nesse processo atuam. Nesse intuito, de acordo com Silva e Cecílio (2007, p.76), os professores:

$$
\begin{aligned}
& \text { [...] "precisam reconhecer e pôr em prática uma concepção de aprendizagem } \\
& \text { mais estreitamente ligada à questão da formação profissional: como ensinar o } \\
& \text { aluno a pôr em prática os seus conhecimentos e, também, como adaptar a } \\
& \text { educação ao trabalho futuro, quando não se pode prever qual será a sua } \\
& \text { evolução". }
\end{aligned}
$$

Nesse contexto, os professores da área de ensino de Ciência e Matemática em Engenharia se defrontam com um problema: a necessidade da construção de uma nova metodologia de ensino que permita às suas disciplinas darem uma maior parcela de contribuição para a formação acadêmica: científica, tecnológica e humanista, solicitada pelas DCNs. Por isso, objetiva-se, 
nesse trabalho, apresentar, como uma proposta de solução a esse problema uma nova metodologia para o ensino de disciplinas da área de Ciência e Matemática em cursos de Engenharia, intitulada de Metodologia dos Problemas Geradores de Discussões ou Metodologia PGD. Para testar os efeitos dessa metodologia, ocorreu a aplicação do PGD Desperdício de Água nas atividades de ensino e aprendizagem de Física em uma turma de alunos recém-ingressos em Engenharia de Produção na UTFPR, câmpus Ponta Grossa, no início do primeiro semestre letivo do ano de 2008.

\section{Influências das DCNs na elaboração dos PGDs}

As condições atuais do mundo do trabalho exigem do aluno egresso no curso de Engenharia, de acordo com as DCNs, um novo perfil, com forte formação científica, tecnológica, humanista e empreendedora (BRASIL, 2002). Buscando indicar parâmetros no sentido de alterar a visão e a prática do docente quanto às mudanças que se fazem necessárias no processo de formação acadêmica, e atender às necessidades profissionais do atual mercado de trabalho, no setor de produção, o Ministério da Educação, por meio das DCNs, estabelece que:

"O perfil dos egressos de um curso de engenharia compreenderá uma sólida formação técnica científica e profissional geral que o capacite a absorver e desenvolver novas tecnologias, estimulando a sua atuação crítica e criativa na identificação e resolução de problemas, considerando seus aspectos políticos, econômicos, sociais, ambientais e culturais, com visão ética e humanística, em atendimento às demandas da sociedade" (BRASIL, 2002, p.03).

E, como ponto de partida das mudanças no ensino de engenharia, as DCNs estabelecem a necessidade de um novo entendimento sobre o currículo:

[...] "o antigo conceito de currículo, entendido como grade curricular que formaliza a estrutura de um curso de graduação, é substituído por um conceito bem mais amplo, que pode ser traduzido pelo conjunto de experiências de aprendizado que o estudante incorpora durante o processo participativo de desenvolver um programa de estudos coerentemente integrado" (BRASIL, 2002, p.02).

Ao analisar as diretrizes, compreende-se que o seu cumprimento, por parte do professor, passa necessariamente por uma mudança de visão sobre a sua ação e sobre os objetivos que estabelece para sua disciplina. O professor precisa enxergar a sua disciplina como uma pequena parte de um todo que é a formação acadêmica. Precisa enxergar a formação acadêmica como apenas uma das etapas de um complexo processo que resultará na formação de um profissional 
que futuramente poderá vir a servi-lo e contribuir para alterações na qualidade de sua vida a partir de suas ações-decisões e os decorrentes efeitos no meio ambiente. Nesse sentido, entendese que o professor precisa questionar-se sobre que tipo de profissional gostaria de ver resolvendo seus problemas e modificando o seu mundo. Certamente a preferência seria por um profissional com comportamento moral e ético, dono de conhecimento técnico e capacidade inovadora necessários para solucionar o problema e capaz de solucioná-lo da forma mais rápida e eficaz. $\mathrm{E}$ que, durante a sua atuação nas indústrias, planeje os procedimentos de produção preocupandose com os possíveis impactos tecnológicos dessa produção. Dessa forma, como introdução à proposta de uma prática para o ensino de Física em engenharia, faz-se necessário comentar o entendimento pessoal de que realizar atividades de ensino e aprendizagem é, por essência, uma atividade de pesquisa. O quê faz um professor em sala de aula? Basicamente a sua função é avaliar se a aplicação das atividades, por ele estabelecidas, de ensino e aprendizagem junto aos seus alunos surtiu o efeito desejado. Contudo, os resultados dessa pesquisa dependem de vários fatores. Dependem da compreensão do pesquisador sobre o problema, dos objetivos estabelecidos, da metodologia de trabalho escolhida, elaborada e sua forma de aplicação, dos instrumentos que se escolhe para realizar a avaliação do processo e da motivação dos sujeitos envolvidos nesse processo. Porém, o que se observa com maior freqüência é que a atividade de avaliação do professor recai apenas sobre as respostas dadas pelos alunos, durante a resolução das provas. A avaliação de um processo de ensino e aprendizagem, não pode ser unilateral, ou seja, não pode focalizar apenas um dos lados do processo. Por entender ensino como a prática do professor, concorda-se com Freire (1982, p.92), quando afirma que:

"Avaliar a prática é analisar o que se faz, comparando os resultados obtidos com as finalidades que procuramos alcançar com a prática. A avaliação da prática revela acertos, erros e imprecisões. A avaliação corrige a prática, aumenta a nossa eficiência".

Logo, ao avaliar, pesquisar ou investigar o ensino, o professor adquire informações que the permitem perceber e corrigir suas próprias falhas e, como conseqüência imediata, contribuir para um efeito/aprendizagem mais consistente a partir da revisão de seu ensino ou de sua prática. Partindo de experiências próprias e apoiado em leituras sobre estudos desenvolvidos por autores, como Freire (1987), Berbel (1998), Fávero e Sousa (2001), Costa e Moreira (2002), Souza e Bastos (2006), Guedes et al (2007), Zanotto e Rose (2004), entende-se, no processo de investigação do ensino e aprendizagem, o desenvolvimento de atividades relacionadas ao ensino por meio de problemas como um caminho importante a ser considerado. Nesse caminho o ensino por meio de problemas vem sendo desenvolvido pelo método da Problematização ou da Atividade Baseada em Problemas, também entendida como Resolução de Problemas. Berbel (1998, p.149) diferencia essas duas estratégias de ensino no seguinte comentário: 


\begin{abstract}
"Na Metodologia da Problematização, os problemas são identificados pelos alunos, pela observação da realidade, na qual as questões de estudo estão acontecendo. Observada de diferentes ângulos, a realidade manifesta-se para alunos e professores com suas características e contradições, nos fatos concretos e daí são extraídos os problemas. A realidade é problematizada pelos alunos. [...] Na Aprendizagem Baseada em Problemas, os problemas são cuidadosamente elaborados por uma Comissão especialmente designada para esse fim. Deve haver tantos problemas quantos sejam os temas essenciais que os alunos devem estudar para cumprir o Currículo, sem os quais não poderão ser considerados aptos para exercer a profissão"
\end{abstract}

Na visão de Freire (1987), toda metodologia que não propuser a participação dos alunos nos chamados "temas geradores", ou seja, na definição dos conteúdos de trabalho a partir da elaboração de problemas por eles mesmo percebidos na realidade, deve ser chamada de "bancária". Dessa forma, Freire, adepto da metodologia da Problematização, faz uma analogia entre o correntista que deposita dinheiro em sua conta e o professor que deposita conteúdos sobre seus alunos. Na visão de Souza e Bastos (2006), Fávero e Sousa (2001), Costa e Moreira (2002), Guedes et al (2007), Zanotto e Rose (2004), a atividade de Resolução de Problemas deve ser elaborada a partir de conhecimentos científicos contextualizados e previamente organizados pelo professor.

Apresenta-se, nesse trabalho, a proposta de ensino por meio dos Problemas Geradores de Discussões -Metodologia PGD- como uma alternativa às metodologias da Problematização e da Resolução de Problemas. Não se propõe a aplicação dos PGDs em qualquer área de estudo ou curso. A elaboração dos PGDs deu-se a partir de orientações específicas para o ensino de Engenharia - DCNs -, porém, entende-se que também podem ser aplicados na área de Ciência e Matemática em cursos superiores de Tecnologias ou utilizados como importante fonte de reflexão junto a acadêmicos e docentes em cursos de formação de professores. A Metodologia PGD, por ter uma aplicação mais restrita - elaborada a partir de objetivos mais definidos-, não se permite à mesma abertura proposta pela metodologia da Problematização, por isso, entende-se que, assim como na Resolução de Problemas, os PGDs devem ser propostos pelo professor e não pelos alunos. Porém, mais do que elaborados sobre conteúdos específicos como ocorre na proposta do Ensino Baseado em Problemas ou Resolução de Problemas, os PGDs devem ser elaborados a partir de situações específicas. Essa situação específica pode ser definida pela escolha de um tema ou um problema gerador e deve ser: contextualizada e voltada para a atividade social/profissional do aluno, futuro egresso em Engenharia. A partir dessa situação é que serão exigidas aplicações de conhecimentos específicos, por parte dos alunos, na busca da solução do problema proposto. Outro ponto importante a ser observado na proposta dos PGDs, 
que a diferencia das demais, encontra-se no fato de que as suas atividades devem ser desenvolvidas, em um primeiro instante, sem absolutamente qualquer forma de intervenção por parte do professor. O processo de diálogo indicado por Freire (1987), de importância indiscutível, diga-se de passagem, é previsto apenas em uma segunda etapa na proposta dos PGDs. Como e por quê? As respostas serão dadas na seqüência.

A escolha dos problemas como base para a proposta dos PGDs deu-se pelo fato de que apresentam como peculiaridade a flexibilidade de sua estrutura. Flexibilidade essa que permite a inserção, em seu enunciado de questões abrangendo diversos aspectos - objetivos de ensino, objetivos do curso, atividades experimentais, ensino de leis e conceitos, questões sociais e ambientais, entre outras - embutidos em uma mesma situação ou tema. Dessa forma, unindo as orientações dadas pelas DCNs à flexibilidade dos problemas, propõe-se que nos cursos de Engenharia ocorram inserções de atividade de ensino e aprendizagem por meio de problemas que gerem discussões. Nesse sentido, propõe-se que os PGDs sejam elaborados de acordo com os seguintes objetivos:

Promover o ensino participativo. Nesse sentido, propõe-se que a atividade PGD ocorra inicialmente em grupos de alunos, sem qualquer tipo de interferência do professor. Busca-se, dessa forma, levar o aluno a exercitar sua habilidade de argumentação e reflexão, a partir do confronto de idéias entre os alunos do grupo, na busca de validar ou não os conhecimentos já adquiridos sobre o tema e, em caso de incerteza coletiva, procurar informações em livros, internet, etc. Reconhecendo a importância do ensino participativo, comentam Souza e Bastos (2006, p.32):

"É importante reconhecer a necessidade do diálogo nas aulas de Ciências da Natureza, Matemática e suas Tecnologias/Física. Para tanto, o professor deve explorar as idéias que surgem dos alunos, tanto na problematização inicial, como na organização e aplicação do conhecimento".

Propor a resolução de um problema real, aplicando teorias à prática e voltado para as futuras atividades profissionais do aluno, pois, de acordo com as DCNs, exigem-se do egresso em Engenharia habilidades e competências para resolver problemas em sua área de atuação profissional. Sobre esse aspecto, comentam Zanotto e Rose (2004, p.49):

[...]" a práxis é importante - se o problema se refere a algo que não se sabe, mas é preciso saber, melhor se este problema estiver relacionado à realidade de quem problematiza, para que a explicação e a solução redundem numa transformação dessa realidade [...] se as estratégias mais elaboradas de organização dependem de instrução direta, é melhor desenvolvê-las em um contexto real, pois esta é uma condição para a aprendizagem significativa". 
Promover a aplicação dos conhecimentos científicos trabalhados pelas disciplinas curriculares à Engenharia. Nesse intuito, a solução do problema proposto pelo PGD deve partir de situações específicas, contextualizadas e relacionadas ao curso de Engenharia que levem o aluno ao uso dos conhecimentos científicos e raciocínio lógico, desenvolvidos na disciplina de ensino e aos que serão apropriados por meio da prática, pesquisas e discussões desenvolvidas durante a atividade de resolução. Segundo Lucero (2006, p.87), esse tipo de atividade contribui sobremaneira para a aquisição de novos conhecimentos científicos por parte dos alunos, pois:
"A medida que va ocurriendo el aprendizaje significativo, la estructura cognitiva del individuo funciona dinámicamente ya que se modifica constantemente, ésta es la construcción que realiza el individuo. Aprender significados es realizar un proceso de construcción, modificando las ideas que se tienen como consecuencia de la interacción con la información nueva".

Promover atividades de ensino que levem o aluno, futuro engenheiro, a conduzir experimentos e interpretar os resultados também é solicitações das DCNs. Por isso, a atividade PGD deve exigir do aluno uma visão ferramental dos conhecimentos científicos. Para tanto, devem ser elaboradas questões que exijam a aplicação desses conhecimentos na realização de atividades experimentais ou, ao menos, a proposição de procedimentos experimentais na busca da solução do problema estabelecido. Esse tipo de atividade além de promover o relacionamento entre a teoria e a prática, contribui para a aprendizagem do aluno, pois, conforme comentam Fávero e Souza (2001, p.145): [...] "o progresso na compreensão da resolução de problema está vinculado ao progresso na compreensão da aprendizagem das tarefas envolvidas na resolução de problemas".

Dar contribuições para o processo de formação da cidadania do futuro profissional da Engenharia. Dessa forma, espera-se que ele possa adquirir consciência cidadã levando-o a atuar profissionalmente de acordo com princípios éticos, responsabilidade profissional, relacionando suas atividades de trabalho com questões sociais e ambientais. Com esse objetivo, durante a elaboração do Problema Gerador de Discussões, deve ser inserida questão que exija do aluno uma análise sobre os efeitos das ciências e tecnologias envolvidas na situação do problema e a sua forma de entender a relevância desses efeitos sobre a sociedade, nos mais diversos aspectos: social, político, ambiental, ético, etc. Berbel (1998, p.144) observa que, na busca de cumprir seus objetivos, os problemas devem ser elaborados com questionamentos:

[...] "intencionalmente selecionados e organizados em cada etapa, de acordo com a natureza do problema em estudo e as condições gerais dos participantes. Volta-se para a realização do propósito maior que é preparar o estudante/ser humano para tomar consciência de seu mundo e atuar 
intencionalmente para transformá-lo, sempre para melhor, para um mundo $e$ uma sociedade que permitam uma vida mais digna para o próprio homem".

Contribuir para o desenvolvimento de competências e habilidades do aluno, solicitadas pelas DCNs, para que possa comunicar-se eficientemente nas formas oral e escrita. Para tanto, na estrutura do PGD deve ser inserida questão solicitando aos alunos a elaboração de relatório escrito sobre as atividades por eles desenvolvidas. Posterior a esse relatório, o professor deve solicitar aos alunos a exposição dos conteúdos de seus respectivos relatórios e a discussão dos procedimentos, conhecimentos científicos e raciocínios adotados na busca da resolução do problema proposto. $O$ processo das discussões ocorrerá sob a mediação do professor permitindoIhe, em primeira instância, corrigir erros procedimentais cometidos pelos alunos e observados pelo professor quando da realização das atividades nos grupos.

As discussões permitirão ao professor perceber e corrigir erros cometidos e ao aluno confirmar ou rejeitar suas propostas, raciocínios, conhecimentos empregados, procedimentos desenvolvidos ou propostos, etc., empregados no processo de resolução do PGD. Ao fim das discussões, o professor deverá solicitar aos alunos a entrega de um relatório final. Nesse relatório final os alunos deverão relatar em que aspectos o processo das discussões lhes fez modificar a forma inicialmente desenvolvida de resolução do PGD, no tocante a conhecimentos científicos e tecnológicos empregados, procedimentos experimentais desenvolvidos ou propostos, raciocínios, etc.

Dessa forma, entende-se que os PGDs podem ser considerados como uma metodologia de ensino, pois, neles há a indicação de um caminho que orienta ao professor, por meio de procedimentos específicos, porém em situações diversificadas, que definem como suas atividades de ensino devem ser trabalhadas em sala de aula de forma a buscar o cumprimento dos objetivos definidos. De forma ainda mais completa, a metodologia PGD prevê caminhos que possibilitarão ao professor fazer uma avaliação do ensino por meio do nível de aprendizagem exteriorizado pelos alunos e observado pelo professor nas diversas etapas da atividade: durante as atividades desenvolvidas pelos alunos no grupo, durante a leitura dos relatórios e as discussões realizadas e após a realização das atividades, quando o professor estiver de posse dos relatórios finais.

\section{A metodologia do trabalho}

Para testar os efeitos da metodologia de ensino baseada nos PGDs, foi desenvolvida uma pesquisa junto a uma turma de quarenta alunos recém-ingressos nos cursos de Engenharia de Produção da UTFPR, câmpus Ponta Grossa, na disciplina de ensino de Física Geral I, no início do primeiro semestre letivo de 2008. Para o desenvolvimento do PGD Desperdício de Água, o professor solicitou aos alunos que trouxessem para a aula: escova, creme dental e um relógio com 
cronômetro. Os outros materiais necessários para o desenvolvimento da pesquisa estiveram à disposição dos alunos no laboratório. Para esclarecimentos aos alunos sobre a atividade a ser desenvolvida, foram repassadas algumas orientações que podem ser observadas no Anexo 1. As atividades do PGD aplicado foram elaboradas de acordo com os seguintes passos:

1- Determinação dos objetivos:

1.1-De ensino/formação: desenvolver atividades que levem o aluno a exercitar suas habilidades e competências para aplicar conhecimentos científicos, experimentais, relacionados à prática do curso de Engenharia, propondo, relatando por escrito e discutindo suas propostas sobre os procedimentos mais adequados, de acordo com questões éticas, políticas, sociais, ambientais, etc., a serem tomados para a resolução do problema proposto.

1.2-Da pesquisa: identificar as falhas na formação média dos alunos, recém-ingressos na Engenharia e verificar se as atividades propostas pelo PGD irão permitir que os objetivos de ensino/formação venham a ser trabalhados.

2-Planejamento das atividades: levando-se em conta o fato de que as metodologias de ensino e pesquisa foram pré-determinadas, o planejamento em questão refere-se à elaboração das questões do PGD. Essas questões devem direcionar as atividades do PGD para o cumprimento dos objetivos de ensino/formação estabelecidos.

3-Aplicação da pesquisa e coleta de dados: as informações foram coletadas a partir dos relatórios entregues pelos grupos de alunos ao professor e pelas anotações realizadas pelo professor durante o acompanhamento e observação das ações desenvolvidas pelos alunos para a resolução do problema e suas contribuições durante o processo de discussão.

4-Análise / avaliação dos resultados obtidos.

5-Retorno ao planejamento: deve ocorrer conforme a necessidade observada, ou seja, à medida que se perceba que as atividades propostas e desenvolvidas não surtiram os efeitos desejados, ou seja, não conseguiram cumprir com os objetivos estabelecidos.

\section{Relato das informações obtidas}

Faz-se necessário comentar que preocupação dos autores ao elaborarem esse relato foi muito maior com a qualificação do que com a quantificação das ocorrências. No relato que se seguirá, as informações que serão apresentadas foram coletadas por meio de observações e anotações do professor, realizadas durante as atividades desenvolvidas pelos alunos, em seus grupos, para a resolução das questões do PGD e também durante o processo das discussões realizadas no grande grupo. Essas informações serão apresentadas intercaladas e sem ordem pré- 
definida, buscando explicitar, da melhor forma que se julgar possível, todos os acontecimentos relacionados a cada uma das etapas da atividade desenvolvida.

Apesar da atividade PGD necessariamente trabalhar com conteúdos de ensino, não haverá, nesse relatório, a preocupação em pormenorizar a forma com que esses conteúdos foram trabalhados e sim indicar se eles foram trabalhados. Dessa forma, priorizar-se-á apenas o relato das atividades não comumente trabalhadas nas salas de aula: efeitos da atividade de resolução de um problema contextualizado e aplicado à realidade do aluno e relacionado à sua futura atividade profissional e a análise das discussões sobre ciência, tecnologia e seus efeitos sobre a sociedade e meio ambiente.

As atividades do PGD Desperdício de Água foram desenvolvidas em função das seguintes questões e questionamentos:

1-Qual o desperdício médio de água causado por uma pessoa ao escovar os dentes com a torneira aberta?

1.1- Descreva os procedimentos experimentais e conhecimentos científicos utilizados pelo grupo para chegar ao resultado solicitado;

1.2- Quais as tecnologias envolvidas na pesquisa e qual a relevância dessa pesquisa para a sociedade?

1.3-Conclusões do grupo sobre a atividade desenvolvida.

\section{Procedimentos desenvolvidos}

As ações dos grupos para determinar o volume de água desperdiçada partiram da determinação da vazão $(Q)$ de água da torneira. A vazão foi obtida pela razão entre o volume de líquido escoado, medido em copo graduado, e o tempo, cronometrado, de escoamento. $\mathrm{O}$ resultado da vazão foi obtido em mililitros por segundo $(\mathrm{ml} / \mathrm{s})$ e essa unidade de medida foi, posteriormente, convertida para o Sistema Internacional. Não foram todos os grupos que conseguiram fazer as conversões corretas entre as medidas. Alguns alunos sequer tinham conhecimento da relação de igualdade entre litro e decímetro cúbico para a medição de volume. Em virtude dessa dificuldade, o professor aproveitou para demonstrar, durante o processo das discussões, a relação entre algumas medidas, entre elas as de volume, e explicou os procedimentos para realizar as conversões de medidas relacionadas ao PGD em questão. Na seqüência os alunos determinaram com o cronômetro o tempo de escoamento de água durante a escovação, pois, concluíram que é durante a escovação que a torneira pode ser fechada, evitando o desperdício. De posse da vazão, determinada anteriormente, e do tempo de escoamento da 
água durante a escovação, os alunos retornaram à equação $Q=V / t$, para obter o volume de água desperdiçado durante uma escovação. Para apenas um dos grupos, que por questão de compreensão do texto, chamaremos de "grupo A", o procedimento adotado foi diferente. Os alunos julgaram ser necessário subtrair do volume de água consumido durante a escovação o volume de pasta de dente utilizado. Para desenvolver o seu raciocínio, armazenaram em um recipiente grande, sem graduação alguma, todo o volume de água e pasta utilizado durante todo o processo de higienização bucal. Para medir esse volume coletado, transportaram-no para copos graduados em mililitros. Determinada a medida do volume total de água e pasta dental, os alunos utilizaram o valor tabelado da densidade da água (d), para determinar a massa (m) correspondente a esse volume. Na seqüência determinaram a massa da pasta dental, em gramas, e a subtraíram da massa total de água e pasta coletada durante a higienização. Dessa forma, o resultado dessa subtração correspondeu à massa de água gasta desperdiçada durante a escovação. Os alunos consideraram que a massa da pasta de dente diluiu-se na água sem provocar alteração significativa na densidade da água.

Durante as discussões, o professor percebeu que a visão dos alunos do "grupo A" sobre a necessidade de subtrair a massa de pasta dental utilizada da massa total de água foi vista por todos os demais alunos como um ponto positivo. Porém, ficou claro para o professor que esses alunos não perceberam que em seus procedimentos esse tipo de consideração, mesmo que indiretamente, também havia ocorrido. Contudo, os alunos do grupo A não deixaram bem claro qual volume de água haviam considerado como desperdiçado, por isso ocorreram alguns questionamentos importantes. $O$ professor comentou que se o volume de água captado fosse o escoado da torneira desde o ato de molhar a escova e a boca até o volume de água gasto para o enxágüe da escova e boca, esse volume não seria correspondente ao volume desperdiçado, seria a soma dos volumes da água utilizada e da água desperdiçada. Em virtude dessa observação, alunos comentaram que o procedimento correto seria reservar o volume de água escoada apenas durante o ato da escovação, como todos os outros grupos haviam feito. Outra observação importante, por parte dos alunos, foi a de que a determinação da massa de água utilizada no processo, pelo grupo A, poderia ser determinada com o simples uso da balança, sem necessariamente precisar de cálculos envolvendo a densidade e o transporte de água "suja" de um recipiente para outro.

Quanto à amostra, observou-se que alunos de dois grupos tiveram o cuidado de medir o tempo de escovação dos quatro membros de suas equipes, utilizando a mesma torneira e com a mesma vazão para obter um valor que, segundo eles, seria mais próximo da realidade. Integrantes de outros grupos criticaram a metodologia dizendo que cada pessoa, ao escovar os dentes, abre torneiras diferentes com vazões diferentes, então, esse procedimento não seria necessariamente o mais correto. Porém, indagados pelo professor, durante as discussões, 
nenhum aluno conseguiu indicar que amostra seria então a ideal para se obter um resultado mais correto. Nessa situação de impasse, o professor aproveitou para inserir conceitos relacionados à teoria dos erros, justificando a necessidade de seguir alguns procedimentos científicos padrões, para a busca da determinação de um valor mais correto de uma medida. Falou-se sobre grandezas físicas, erros, algarismos significativos, desvios e valor mais provável de uma medida.

Finalizaram-se as discussões sobre os procedimentos com o professor fazendo a indicação e explicando algumas variáveis que devem ser consideradas durante a coleta de dados para o desenvolvimento dessa pesquisa: tipo de torneira, pressão da água, diâmetro do bocal da torneira, abertura do registro, tempo de escovação, entre outras. Porém, da mesma forma com que o aluno tem que se preocupar com as variáveis que influenciam nos resultados da pesquisa, precisa definir as questões que delimitam essa pesquisa. E, entre essas questões, o professor comentou que os alunos precisam definir a periodicidade de ocorrência do fenômeno que está sendo analisado. O desperdício de água durante uma escovação, em um dia ou um mês? Os alunos precisam definir o sujeito envolvido no fenômeno. Desperdício causado por alunos de Engenharia, por moradores de uma favela, por velhinhos em um asilo? Dessa forma, buscou-se desenvolver melhor compreensão sobre a importância da definição dos objetivos para que se possam planejar as atividades desenvolvidas buscando um resultado mais significativo.

\section{Tecnologias envolvidas e relevância da pesquisa}

Após leitura dos relatórios, o professor percebeu que os alunos apresentaram um conceito restrito sobre tecnologia, sendo reduzida aos produtos tecnológicos. Dessa forma, os alunos, durante as discussões, citaram como tecnologias envolvidas o uso do lápis, calculadora, torneira, copo graduado, régua, balanças, pasta dental, relógio de pulso, entre outros. Dessa forma, viu-se a necessidade de esclarecer durante as discussões, que também os conhecimentos científicos: matemáticos e físicos utilizados pelos alunos ou mesmo metodologia por eles desenvolvida para a solução do PGD, fazem parte de processos tecnológicos. Porém, também se utiliza de tecnologia para tratar a água e para permitir a sua distribuição às residências. Infelizmente o tempo estabelecido para o desenvolvimento da atividade não permitiu que fossem aprofundadas discussões sobre a influência de cada um desses produtos tecnológicos diretamente sobre a vida do homem.

A respeito da relevância da pesquisa para a sociedade os alunos se preocuparam em relatar o problema da escassez de recursos hídricos limpos no planeta e a importância de ações do governo para buscar a conscientização da população quanto à questão do desperdício. Alguns alunos comentaram sobre a importância da higienização bucal como fonte de saúde geral para o homem e que não se poderia pensar em economizar água a ponto de provocar a diminuição da 
qualidade dessa higienização. Aproveitando o ensejo, o professor frisou que "o desperdício deve ser sempre combatido, seja do que for: de água, alimentos, energia, matéria prima, tempo, etc. E essa preocupação deve também ocorrer no setor de produção, pois a competitividade no mercado está acirrada e um dos fatores que pode ser determinante no aumento dos lucros ou até mesmo na questão de sobrevivência de uma empresa pode estar relacionado à economia de recursos. Por isso, as empresas têm valorizado os projetos e/ou programas, criados ou ações desenvolvidas por seus empregados, com o intuito de promover a diminuição de desperdícios. Dessa forma, os alunos precisam entender a atividade de planejamento como uma das mais importantes no processo de produção e, nesse planejamento, há a necessidade de se utilizar de conhecimentos científicos para poder conhecer as variantes em torno da atividade desenvolvida, porém, sem desvincular o uso desses conhecimentos com questões sociais e ambientais.

\section{Conclusões}

Os resultados numéricos encontrados pelos grupos e apresentados durantes as discussões, indicaram um desperdício de água que variou entre seis a nove litros por pessoa em uma única escovação. Por isso, os alunos comentaram a necessidade de promover a conscientização das pessoas com relação ao problema da falta de água potável e procuraram apresentar valores impactantes como o volume de água desperdiçado pela população da cidade de Ponta Grossa durante o período de um ano, se todas as pessoas escovassem seus dentes com as torneiras abertas.

Percebeu-se, em alguns casos, a falta de informação dos alunos e a despreocupação em buscar mais informações que lhes permitissem contribuir de forma mais efetiva no processo das discussões. Um dos grupos, por exemplo, concluiu que da conscientização das pessoas sobre a necessidade de evitar esse desperdício de água durante a escovação poderia depender a vida no planeta. Partindo dessa afirmação, o professor aproveitou, durante o processo das discussões, para esclarecer aos alunos sobre a necessidade de que durante a resolução de um problema se busque a sua visualização de uma forma mais ampla, relacionando-o com a realidade de dentro e fora da sala de aula. Dependendo da amplitude dessa visão, pode-se interpretar, analisar e avaliar de forma errada os fenômenos envolvidos, variáveis que influenciam o fenômeno, e as influências desses fenômenos ou acontecimentos sobre os processos na produção industrial, na sociedade, no ambiente, etc. Após a intervenção do professor, um aluno que mora e trabalha em uma cidade da região, comentou que a indústria em que ele trabalha consome em um único dia o mesmo volume de água consumido em um mês por toda a população da cidade, cerca de 20.000 habitantes. O professor complementou a informação, comentando que se em uma escovação são consumidos aproximadamente 8 litros de água, de acordo com o que eles determinaram, ao dar- 
se uma descarga no vaso de um banheiro, são consumidos cerca de 20 litros. Por isso, concluiu o professor, os alunos deveriam preocupar-se em compreender melhor as situações no entorno do problema, ou seja, buscar sempre mais e mais informações buscando entender o problema em toda a sua complexidade.

Outras discussões ocorreram em função do título dado pelos grupos à atividade desenvolvida. Uma das equipes deu ao trabalho o simples título de "Desperdício". O professor reiterou o comentário de que "desperdício" pode ser de alimento, energia, tempo, matéria prima, etc., e, se for desperdício de água, há que se considerar situações em que as pessoas também desperdiçam água ao tomar banho demorado, ao lavar o carro ou a calçada com a torneira sempre aberta. Porém, e de forma ainda mais grave, há indústrias que gastam volumes enormes de água sem se preocupar com fontes alternativas ou com a reutilização/ reciclagem da água, ou com um o tratamento dos fluidos residuais que são despejados diretamente nos rios provocando problemas no eco-sistema. Precisam entender que o problema também é político, pois, a falta de vontade política faz com que não ocorram investimentos no saneamento básico, entenda-se tratamento de esgotos residenciais que também contribuem para a contaminação das fontes de águas naturais. Dessa forma, o professor buscou orientar aos alunos sobre a importância do engenheiro no processo de produção, pois, cabe a esse profissional planejar o processo, levando em consideração quantidade e qualidade, mas também, com os efeitos dessa produção sobre a sociedade e o ambiente.

Outra discussão interessante surgiu a partir do comentário de um grupo de alunos que citou o uso das "torneiras tecnológicas," desenvolvidas com uma tecnologia que permite com que sejam abertas com um simples toque e que, depois de um determinado tempo, fecham-se sozinhas. Segundo esses alunos, essa nova tecnologia também provoca desperdício. Muitas vezes, comentaram os alunos, o volume de água liberado durante o uso dessa torneira é superior ao volume de água necessário pelo usuário. O professor comentou que a conclusão desses alunos é válida, no aspecto por eles observado. Porém, concluiu o professor, pessoas não-conscientes usam torneiras em prédios públicos e as deixam deliberadamente abertas, da mesma forma que alguns alunos, deixam as luzes acesas ao saírem da sala de aula. Dessa forma, numa visão mais ampla do entorno do problema, permite-se determinar que a torneira tecnológica pode ser benéfica, pois pode evitar o desperdício de água quando instalada em locais públicos.

\section{Considerações finais}

O processo de formação do engenheiro é bastante complexo, por isso, entende-se que não será concluído apenas com a formação acadêmica ou com a formação dada por uma disciplina e muito menos pela inserção de uma única atividade de ensino desenvolvida e aplicada 
na primeira semana de aula, junto a alunos recém-ingressos. Nesse processo, a formação acadêmica, ainda que seja apenas uma das etapas, apresenta as suas próprias prerrogativas que se alteram de acordo com o panorama apresentado. No panorama atual, percebe-se questões sociais e ambientais sofrendo influências e/ou influenciando a produção de novas tecnologias em um planeta em constante transformação. Das indústrias exige-se maior planejamento: controle dos resíduos da produção e elaboração de tecnologias com redução nos impactos sociais e ambientais. Das universidades exige-se a formação de profissionais capacitados para trabalhar desempenhando diferentes funções, com competência científica, técnica e tecnológica e com consciência de sua responsabilidade enquanto profissional e cidadão.

A Metodologia PGD foi apresentada nesse trabalho para indicar uma forma para que os professores de Ciência e Matemática possam adaptar sua prática de ensino às orientações das DCNs, frente ao novo padrão de formação acadêmica exigida junto ao futuro profissional de Engenharia. Foram observadas, com a aplicação do PGD Desperdício de Água, algumas dificuldades iniciais apresentadas pelos alunos ao desempenhar as tarefas solicitadas pelo PGD: dificuldades em realizar atividades em grupo, em aplicar conhecimentos científicos básicos, dificuldades em se expressar na forma oral e escrita, dificuldades em relacionar atividades de sala de aula com questões reais, resultando em uma visão mais superficial sobre os processos analisados, entre outros. Entende-se, contudo, que essas dificuldades ocorreram em função das deficiências decorrentes da formação média desses alunos e não em função do PGD. Por isso, mesmo com as dificuldades apresentadas, observa-se no relato apresentado que as atividades desenvolvidas pelos alunos por meio do PGD contribuíram de forma positiva para a promoção da participação do aluno no processo de aprendizagem. Promoveram o exercício do confronto de idéias, de reflexões, de discussões e de aplicação de raciocínios, conceitos e equações da Física em atividades de resolução de um problema real, vinculando questões profissionais às questões éticas, morais, sociais, políticas e ambientais.

A aplicação da Metodologia PGD no ensino de Ciência e Matemática em Engenharia pode contribuir para despertar no aluno o hábito de avaliar o uso, a aplicação de tecnologias e o desenvolvimento de processos tecnológicos também a partir de suas implicações sociais e ambientais. Entende-se, dessa forma, que os PGDs podem desempenhar importante papel para a formação humanística do acadêmico, pois, com a aquisição de novos valores promove-se o desenvolvimento de uma maior consciência do aluno enquanto cidadão e futuro profissional a ser inserido no mercado de trabalho. 


\section{Referências}

AULER, D. ; BAZZO, W.A. Reflexões para a implementação do movimento CTS no contexto educacional brasileiro. Ciência \& Educação, v.7, n.1, p.1-13, 2001.

BELHOT, R.V. A didática no ensino de engenharia. Anais do XXXIII Congresso Brasileiro de Ensino de Engenharia. Campina Grande, 2005.

BERBEL, N.A.N. A problematização e a aprendizagem baseada em problemas: diferentes termos ou diferentes caminhos? Interface-Comunicação, Saúde, Educação, v.2, n.2,p.139-154, 1998.

BRASIL. CNE/CES 11, de 11 de março de 2002, que institui as Diretrizes Curriculares Nacionais do Curso de Graduação em Engenharia. Brasília: Ministério da Educação, 2002. Disponível em <http://www.abepro.org.br>. Acesso em 07/12/07.

COSTA, S.S.C. ; Moreira, M. A. O Papel da Modelagem Mental dos Enunciados na Resolução de Problemas em Física. Revista Brasileira de Ensino de Física, vol. 24, no. 1, Março, 2002.

FÁVERO, M. H.; SOUSA, C. M. S. G. A resolução de problemas em Física: revisão de pesquisa, análise e proposta metodológica. Revista Investigações em Ensino de Ciências, Porto Alegre, Brasil, v. 6, n. 2, p. 143 - 196, $2001 . \quad$ Disponível em <http://www.if.ufrgs.br/public/ensino/vol6/n2> . Acesso em 05/01/2008.

FREIRE, P. A importância do ato de ler. Ed.13. Cortez Editora. São Paulo, 1982.

FREIRE, P. Pedagogia do oprimido. $17^{\mathrm{a}}$ Ed. Editora Paz e Terra. Rio de Janeiro. 1987.

GORDILLO, M. M.; Galbarte, J.C.G. Reflexiones sobre la educación tecnológica desde el enfoque CTS. Revista Iberoamericana de Educación, n.28. OEl. Madrid 2002. Disponível em http://www.rieoei.org, acesso em 21/04/2008.

GUEDES, N.G., et al. A metodologia da problematização na Escola de Posturas da UFPB: um processo emancipatório na prática da educação gerontológica. Revista Eletrônica de Enfermagem. v.09, n.02, p.298-314, 2007. Disponível em http://www.fen.ufg.br, acesso em 05/04/2008.

LAUDARES, J. B. ; Ribeiro, S. Trabalho e formação do engenheiro. Revista Brasileira de Estudos Pedagógicos, v. 81, n. 199, p. 491-500, Brasília, set./dez. 2000.

LUCERO, I. et al. El análisis cualitativo en la resolucion de problemas de física y su influencia en el aprendizaje significativo. Revista Investigações em Ensino de Ciências, v.11, n.01, pp. 85-96, 2006. 
MEIRELLES, M. et al. O papel da Engenharia de produção. Anais do XXXIII Congresso Brasileiro de Ensino de Engenharia. Campina Grande, 2005.

PIRATELLI, C. L. A Engenharia de Produção no Brasil. Anais do XXXIII Congresso Brasileiro de Ensino de Engenharia. Campina Grande, 2005.

PÓVOA, J. M. ; BENTO, P.E.G. O Engenheiro, sua formação e o mundo do trabalho. Anais do XXXIII COBENGE. Campina Grande, 2005.

SANTOS, M.V.M. Cidadania, conhecimento, ciência e educação CTS. Rumo a "novas" dimensões epistemológicas. Revista CTS, no 6, vol. 2, p.137-157, Portugal, 2005.

SILVA, L.P. ; CECíLIO, S. A mudança no modelo de ensino e de formação na Engenharia. Educação em Revista, Belo Horizonte, v. 45. p. 61-80. 2007.

SILVEIRA, M. A. A formação do engenheiro inovador: uma visão internacional. Rio de Janeiro, PUC-Rio, Sistema Maxwell, 2005.

SOUZA, C.A. ; BASTOS, F.P. Um Ambiente Multimídia e a Resolução de Problemas de Física. Revista Ciência \& Educação, v. 12, n. 3, p. 315-332, 2006.

ZANOTTO, M.A.C.; ROSE, T.M.S. Problematizar a própria realidade: análise de uma experiência de formação contínua. Revista Educação e Pesquisa, São Paulo, v.29, n.1, p. 45-54, 2003.

\section{Anexo: Orientações aos alunos sobre a atividade PGD}

1- As atividades serão realizadas em grupos de quatro alunos;

2- O tempo de desenvolvimento da atividade será de aproximadamente três horas, dividido entre: planejamento, desenvolvimento da pesquisa, elaboração e entrega ao professor de um relatório, apresentação do relatório por uma equipe sorteada e discussões;

3- O professor não irá intervir de forma alguma nas atividades desenvolvidas pelos grupos para a resolução do problema, a não ser, no processo de discussões sobre os relatórios. 0 professor irá, durante as discussões, expor as idéias, sem citar os autores, contidas nos relatórios. Nas discussões, todos deverão participar, para que se possa chegar a um entendimento sobre $o$ melhor caminho para a resolução do problema e a conclusões mais significativas;

4- Para a construção do relatório, serão exigidos: título da pesquisa, nome dos alunos do grupo, ações desenvolvidas, tecnologias envolvidas no processo, relevância da pesquisa perante a 
sociedade no tocante aos aspectos sociais, morais, éticos, políticos e ambientais e, por fim, as conclusões do grupo;

5- A escolha do tema a ser pesquisado na atividade deu-se em função do ementário da disciplina de Física Geral I, por isso, o problema deve permitir o trabalho dos conhecimentos relacionados aos conteúdos: Sistemas de Unidades de Medidas e Teoria dos Erros e, que para a sua resolução, serão necessários o uso de raciocínio lógico e conhecimentos científicos já apropriados;

6- Os alunos poderão dirigir-se à biblioteca para realizar pesquisa caso julguem necessário o uso de um raciocínio ou conhecimento que considerem faltar domínio.

Vinícius Machado - Universidade Tecnológica Federal do Paraná, câmpus Ponta Grossa vinmac@utfpr.edu.br

Nilcéia Aparecida Maciel Pinheiro - Universidade Tecnológica Federal do Paraná, câmpus Ponta Grossa-nilceia@utfpr.edu.br 